\title{
Lumbar extradural dumbbell cavernous hemangioma: A rare lesion
}

\author{
Dinesh Shukla, Vinjamuri Srinivasa Rao, Alugolu Rajesh, Megha Shantveer Uppin¹, Anirrudh Kumar Purohit \\ Departments of Neurosurgery, and ${ }^{1}$ Pathology, Nizam's Institute of Medical Sciences, Hyderabad, Andhra Pradesh, India
}

\begin{abstract}
A 52-year-old female presented with slowly progressive left lower limb polyradiculopathy. MRI of the lumbar region revealed an extradural dumbbell mass at $\mathrm{L}_{3}$ vertebral level, isointense on $\mathrm{T}_{1} \mathrm{~W}$ and hyperintense on $\mathrm{T}_{2} \mathrm{~W}$ images with homogenous contrast enhancement and extending into paraspinal region through left $\mathrm{L}_{3} / 4$ foramen. $\mathrm{L}_{2}$ to $\mathrm{L}_{4}$ left hemilaminectomy and excision of intraspinal part of tumor was performed. Histopathological examination revealed presence of cavernous hemangioma. This case is reported because of its rarity, unusual dumbbell shape of lesion and difficulty in making a preoperative diagnosis without a coexisting bone lesion.
\end{abstract}

Key words: Cavernous hemangioma, dumbbell, extradural, schwannoma

\section{Introduction}

Cavernous hemangioma is a benign vascular malformation and belongs to a wide and continuous overlapping spectrum of hamartomas. ${ }^{[1]}$ The cavernous angiomas occur most commonly intraaxially in cerebral hemisphere, brainstem and cerebellum. However, they can occur in any part of the neruraxis including spine. ${ }^{[2,3]}$ Most cavernous haemangiomas occur in the vertebral body and may extend into the epidural space. Purely extradural cavernous hemangiomas without any vertebral body involvement is extremely rare and accounts for only $4 \%$ of all extradural spinal tumors and $12 \%$ of haemangiomas occurring extradurally. ${ }^{[4,5]}$ We herein present a rare case of extradural dumbbell lumbar (L3) cavernous hemangioma with paraspinal extension.

\section{Case Report}

A 52-year-old female presented with insidious onset progressive low backache with pain radiating to whole

\begin{tabular}{|l|l|}
\hline \multicolumn{2}{|c|}{ Access this article online } \\
\hline Quick Response Code: & Website: \\
\hline & www.ruralneuropractice.com \\
\cline { 2 - 3 } & \\
\hline & DOI: \\
\hline
\end{tabular}

of left lower limb associated with paraesthesias for two months. She had difficulty in walking due to pain. There were no symptoms suggestive of bladder or bowel involvement. General examination was unremarkable. Upper limbs were normal with no sensorimotor deficits. Left lower limb power was $4 / 5$ in hip flexion, extension, abduction and adduction, $4 / 5$ in knee flexion and extension, subtle weakness in ankle flexion and extension and great toe extension with hypotonia. Right side lower limb power was normal. The reflexes of left lower limb were sluggish whereas on right side they were brisk (normal). Sensory examination revealed impairment of all the modalities of sensations (pin prick, touch, temperature, vibration- impaired upto anterior superior iliac spine) from L2 to S4 dermatomes on left side. There was no spinal tenderness or deformity. Rest of examination was unremarkable. Magnetic resonance imaging of lumbar spine revealed an irregularly shaped, well defined extradural lesion at L3 vertebral level indenting the body, displacing the thecal sac posterolaterally and extending into left paraspinal region through L3- 4 neural foramen. Lesion was isointense on $\mathrm{T} 1 \mathrm{~W}$, hyperintense on $\mathrm{T} 2 \mathrm{~W}$ images with strong homogenous enhancement on Gadolinium contrast study [Figure 1]. Provisional preoperative diagnosis of schwannoma was considered. Though the clinical findings and radiology were not concordant, the patient was suggested surgical intervention for the presence of enhancing mass lesion noted on the imaging with guarded prognosis.

\section{Address for correspondence:}

Dr. Dinesh Shukla, Department of Neurosurgery, Nizam Institute of Medical Sciences, Hyderabad, Andhra Pradesh, India.

E-mail: dineshshukla2002@yahoo.co.in 
The patient underwent left hemilaminectomy from L2 to L4. There was an extradural, brownish red, highly vascular mass located anterolateral to thecal sac at L3 vertebral body with well defined capsule around it. It was extending into left paraspinal region through L3/4 neural foramen. Left L3 nerve root was pushed superiorly by the tumor and it was not arising from any neural tissue. It was highly vascular and bleeding heavily on taking a small biopsy. The capsule was then coagulated to control the haemorrhage. It was dissected clear from the L3 nerve and the dura keeping the dissection over the coagulated capsule. The spinal component of the lesion was excised in toto until the neural foramen, where it was coagulated and was cut sharply leaving behind the extra-foraminal portion. Perfect haemostasis was achieved using bipolar cauterisation, cross checked by Valsalva manoeuvre. Scalloping of L3 vertebral body was noted following tumor excision.

Microscopic examination revealed numerous dilated vascular channels of variable sizes lined by a single layer of flattened epithelial cells and filled with blood elements. Interspersed thick hyalinised blood vessels and mature adipose tissues were noted [Figure 2]. The histological picture was characteristic of cavernous hemangioma. Radiotherapy was administered to the residual paraspinal portion of tumor [Figure 3]. For radiotherapy, the patient was immobilised in a vacuum locking device and CT simulation was done in the treatment position. CT images were fused with the preoperative and post operative MR images. Margin of $1 \mathrm{~cm}$ was added to the post contrast T1W MRI to obtain the clinical target volume; planning target volume was obtained by adding a margin of $0.5 \mathrm{~cm}$ to the clinical target volume. Dose was prescribed to the planning target volume. Three dimensional conformal radiotherapy was planned on ECLIPSE ${ }^{\mathrm{TM}}$ planning system (Varian Medical systems, Palo alto, CA) on linear accelerator (Clinac iX-3665) using $6 \mathrm{MV} X$ rays. The dose prescription was $40 \mathrm{~Gy}, 2$ Gy per fraction, 20 fractions given five days a week over five weeks.

\section{Discussion}

Cavernous hemangioma is a benign vascular malformation, also known as cavernous malformation, cavernous angioma or cavernoma. The cavernous angiomas occur in two forms: sporadic and familial. Ten per cent of all cavernomas are familial. ${ }^{[6]}$

The cavernous hemangiomas occur throughout the neuroaxis including both intracranial and spinal compartments. According to location, its incidence in supratentorial, infratentorial and spinal compartments is $80 \%, 15 \%$ and $5 \%$ respectively. ${ }^{[7]}$

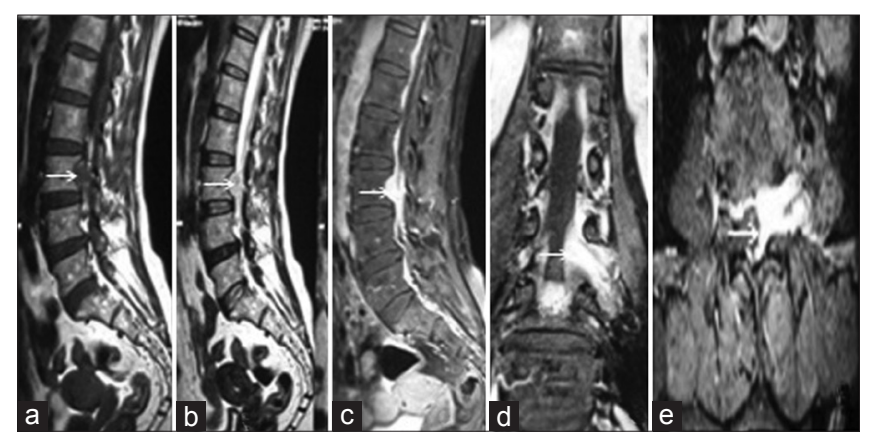

Figure 1: Shows irregularly shaped well defined extradural lesion (arrows), hypointense on T1W (a), hyperintense on T2W (b) images with homogenous contrast enhancement (c, d, e) and paraspinal transforaminal extension $(d, e)$

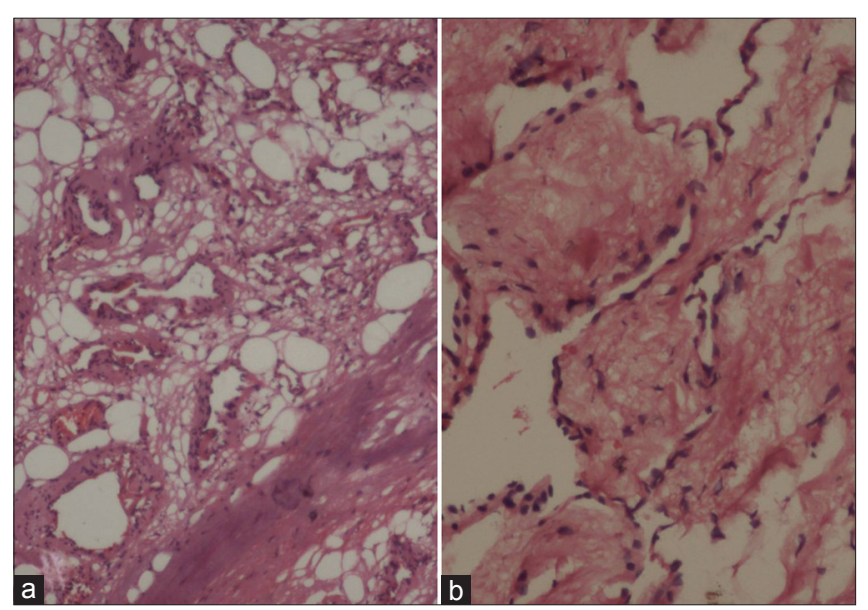

Figure 2: $(a, b)$ The proliferating and anatomizing capillary channels lined by endothelial cells $(H$ and $E, \times 100)$

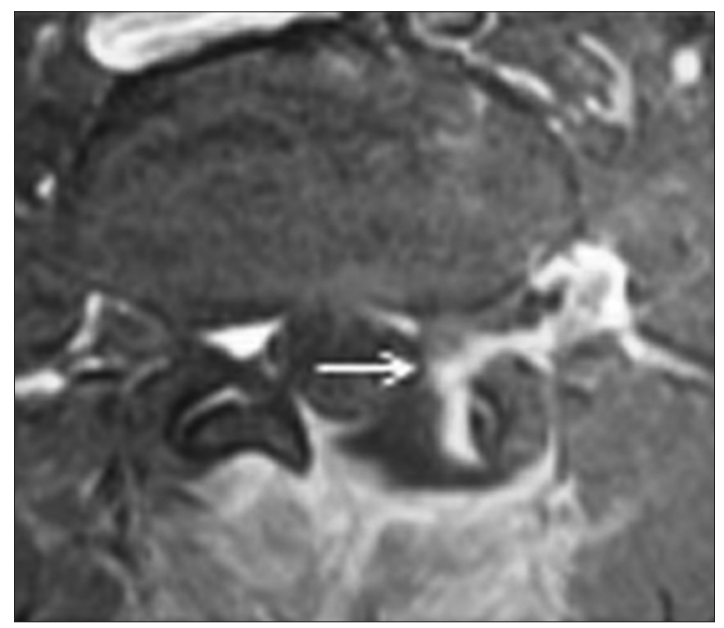

Figure 3: Shows postoperative changes (arrow) in spinal canal and residual tumor in paraspinal region

Purely extradural spinal cavernous hemangiomas are rare and the extension through intervertebral foramen into extraspinal region (dumbbell) is still rarer. In that case, it can be confused with commonly diagnosed nerve sheath tumors. ${ }^{[8]}$ The onset of symptoms in these spinal cavernomas may be acute, progressive or remittent, 
depending on the biological behavior of the tumor. Lumbar extradural hemangiomas behave differently, not only from intramedullary cavernous hemangiomas but also from extradural cavernomas of other spinal locations. ${ }^{[9]}$ Purely extradural hemangiomas should be included in the differential diagnosis of lumbar extradural soft-tissue lesions. ${ }^{[10]}$

In contrast to intracerebral cavernous hemangiomas, the patterns of density on CT scans and signal intensity on MR images are more homogenous in extradural hemangiomas. Another point of differentiation is the absence of low signal rim (hemosiderin) which is usually seen in intraaxial spinal cord cavernomas. As seen in present case, extradural cavernous hemangiomas are usually isointense on T1W and hyperintense on T2W images and show homogenous contrast enhancement because of the presence of sinusoidal channels. ${ }^{[11]}$

The lesion should be differentiated from other epidural neoplastic or inflammatory conditions, such as meningioma, neurofibroma, lymphoma, hemorrhagic vascular mass, granuloma and angiolipoma. ${ }^{[1,1]}$

Complete and in toto excision of the lesion should be attempted for clinical improvement; however, in case of subtotal excision, adjuvant radiotherapy is advised. ${ }^{[12]}$ Radiosurgery as primary or adjuvant therapy is increasingly becoming an option as advances in radiosurgical equipment are enabling safe and accurate targeting of lesions. ${ }^{[13]}$

\section{Conclusion}

Though purely extradural cavernomas are rare in occurrence, they should be considered as possible differential diagnosis of dumbbell lesions of spine in view of operative nuances (especially massive haemorrhage) and management thereof.

\section{References}

1. Graziani N, Bouillot P, Figarella-Branger D, Dufour H, Peragut JC, Grisoli F. Cavernous angiomas and arteriovenous malformations of the spinal epidural space: Report of 11 cases. Neurosurgery 1994;35:1202-63.

2. Padovani R, Poppi M, Pozzati E, Tognetti F, Querzola C. Spinal epidural hemangiomas. Spine (Phila Pa 1976) 1981;6:336-40.

3. Robinson JR, Awad IA, Little JR. Natural history of the cavernous angioma. J Neurosurg 1991;75:709-14.

4. Morioka T, Nakagaki H, Matsushima T, Hasuo K. Dumbbell-shaped spinal epidural cavernous angioma. Surg Neurol 1986;25:142-4.

5. Padovani R, Tognetti F, Proietti D, Pozzati E, Servadei F. Extrathecal cavernous hemangioma. Surg Neurol 1982;18:463-5.

6. Palur RS, Ravikumar CV, Satish S, Rao BR, Shekar GR. Developmental vascular abnormalities of the central nervous system-other than AVM's. In: Venkataraman S, editor. Progress in clinical neurosciences. Neurological Society of India; 1999. p. 151-72.

7. Labauge P. Familial forms of central nervous system cavernomas: From recognition to gene therapy. Neurochirurgie 2007;53:152-5.

8. Iglesias S, Ayerbe J, Sarasa JL, Sousa P, Torres C, Ruiz-Barnés P. Dumbbell-shaped spinal epidural cavernous angioma. Case report and review of the literature. Neurocirugia (Astur) 2008;19:248-53.

9. Tekkök IH, Akpinar G, Güngen Y. Extradural lumbosacral cavernous hemangioma. Eur Spine J 2004;13:469-73.

10. Rovira A, Rovira A, Capellades J, Zauner M, Bella R, Rovira M. Lumbar extradural hemangiomas: Report of three cases. AJNR Am J Neuroradiol. 1999;20:27-31.

11. Aoyagi N, Kojima K, Kasai H. Review of spinal epidural cavernous hemangioma. Neurol Med Chir (Tokyo) 2003;43:471-5.

12. Padovani R, Acciarri N, Giulioni M, Pantieri R, Foschini MP. Cavernous angiomas of the spinal district: Surgical treatment of 11 patients. Eur Spine J 1997;6:298-303.

13. Sohn MJ, Lee DJ, Jeon SR, Khang SK. Spinal radiosurgical treatment for thoracic epidural cavernous hemangioma presenting as radiculomyelopathy: Technical case report. Neurosurgery 2009;64:E1202-3.

How to cite this article: Shukla D, Rao VS, Rajesh A, Uppin MS, Purohit AK. Lumbar extradural dumbbell cavernous hemangioma: $A$ rare lesion. J Neurosci Rural Pract 2013;4:207-9.

Source of Support: Nil. Conflict of Interest: None declared. 